\title{
Atividade de desenho como mediadora de interações sociais entre crianças ${ }^{1}$
}

\author{
Talita Pereira Dias ${ }^{2}$ \\ Nancy Vinagre Fonseca de Almeida \\ Universidade Federal de São Carlos, São Carlos-SP, Brasil
}

\begin{abstract}
Resumo: O presente trabalho objetivou analisar a ocorrência de tipos de interações sociais que emergem entre crianças de diferentes idades, durante quatro situações de desenho (com giz de cera ou com guache; individualmente ou em conjunto). Participaram 28 crianças, de uma creche da cidade de São Carlos-SP, entre dois e cinco anos de ambos os sexos, divididas em quatro grupos etários. Foram transcritas quatro horas de videogravações. As interações identificadas foram classificadas a partir de um sistema de categorias. Os principais resultados indicaram: ocorrência de 728 interações, com maior frequência em crianças de quatro anos e menor com as de dois anos; na condição guache/juntos, ocorreu maior porcentagem de interações para a maioria dos grupos; na condição giz de cera/individual, houve menor porcentagem; categorias interativas com maior destaque foram Descrição e Imitação e com menor, Enredo. O estudo evidenciou que a atividade de desenho promove diversidade de interações sociais entre crianças.
\end{abstract}

Palavras-chave: interação social, desenho, desenvolvimento infantil.

\section{Drawing as a mediator of social interactions among children}

\begin{abstract}
This study aimed to analyze the occurrence of social interactions among children of different ages during four drawing situations (with crayons or gouache, individually and in group). Twenty-eight boys and girls from a daycare in São Carlos-SP, Brazil, between two to five years of age, participated in the study and were divided in four groups according to age. A total of four hours of video recording were transcribed. Identified interactions were classified according to a system of categories. The main results indicate the occurrence of 728 interactions, with higher frequency among 4-year-old children and lower frequency among 2-year-old; more interactions occurred in the majority of groups in the gouache/group condition and a lower frequency of interaction occurred in the crayons/individually condition; the interactive categories that stood out the most were Description and Imitation and Plot was the least frequent category. This study evidenced that drawing promotes a variety of social interactions among children.
\end{abstract}

Keywords: social interaction, drawing, childhood development.

\section{El dibujo como mediador de interacciones sociales entre niños}

\begin{abstract}
Resumen: El presente trabajo tuvo por objetivo analizar la ocurrencia de tipos de interacciones sociales que emergen entre niños de diferentes edades en cuatro situaciones de dibujo (con crayón de cera o con témpera, individualmente o en grupo). Participaron 28 niños y niñas, de guardería infantil en la ciudad de São Carlos-SP, Brasil entre dos y cinco años, divididos en cuatro grupos etáreos. Cuatro horas de filmación fueron transcritas e interacciones fueron identificadas y clasificadas por un sistema de categorías. Los principales resultados indicaron: ocurrencia de 728 interacciones, con mayor frecuencia con niños de cuatro años y menor con niños de dos años; en la situación tempera/juntos ocurrió mayor por ciento de interacciones para la mayoría de los grupos, en condición crayón de cera/individual hubo menor frecuencia; categorías interactivas con mayor relevancia fueron Descripción e Imitación y con menor, Desarrollo de un tema. El estudio evidenció que las actividades de dibujo promueven una variedad de interacciones sociales entre niños.
\end{abstract}

Palabras clave: interación social, diseño, desarrollo infantil.

Vários estudiosos têm demonstrado, por meio de investigações, a importância dos processos interativos para o desenvolvimento dos indivíduos, desde a concepção até a morte (Amorim, Vitória, \& Rossetti-Ferreira, 2000; Colaço, 2004; Gil \& Almeida, 2000; Vygotsky 1988). A premissa de que o ser humano desenvolve-se mediante as interações sociais que vivencia é central na obra de Vygotsky (1988). Para este autor, a construção social do indivíduo dá-se com base em uma história de relações com outros, por meio da linguagem

1 Este texto foi revisado seguindo Acordo Ortográfico da Língua Portuguesa (1990), em vigor a partir de $1^{\circ}$ de janeiro de 2009.

2 Endereço para correspondência:

Talita Pereira Dias. Universidade Federal de São Carlos. Centro de Educação e Ciências Humanas. Programa de Pós-graduação em Psicologia. Rodovia Washington Luís, km 235. CEP 13.565-905. São Carlos-SP, Brasil.E-mail: talitapsi10@yahoo.com.br e de transformações das funções psicológicas, ambas constituídas tanto pelas interações face a face como pelas relações mais abrangentes, como a cultural (Isaia, 1998).

A inserção da criança no ambiente pré-escolar é singular para o desenvolvimento infantil, uma vez que esse novo contexto oferece diferentes condições de cuidados, educação, desenvolvimento e relações (Lordelo \& Carvalho, 1998). Esse ambiente requer adaptações e aquisições por parte da criança, em especial porque os parceiros mais disponíveis são as próprias crianças, o que representa novas alternativas de interação e, assim, ampliação do repertório social (Gil \& Almeida, 2005; Amorim, Eltink, Vitória, Almeida, \& Rossetti-Ferreira, 2004). Além da inserção no contexto pré-escolar, outro fator consensualmente relevante para ampliação do repertório social refere-se à idade, de forma que, no decorrer do desenvolvimento, a criança passa a assimilar cada vez mais normas, valores e expectativas de seu ambiente e aprende padrões 
de comportamentos sociais cada vez mais complexos (Del Prette \& Del Prette, 2005).

Branco e Mettel (1995) destacam alguns estudos que apontam para os aspectos do desenvolvimento favorecidos pelas interações entre crianças, como estes: superação do egocentrismo, desenvolvimento de comportamentos pró-sociais, de atitudes (Camaioni \& Youniss, conforme citados por Branco e Mettel), oportunidades de conflitos sociocognitivos (Ellis \& Gauvain, conforme citados por Branco e Mettel), capacidade de empatia (Le Mare \& Rubin, conforme citados por Branco e Mettel), padrões de comportamento, atitudes e valores, julgamento moral e autoconceito (Bloch \& Pelegrini; Carvalho \& Beraldo, conforme citados por Branco e Mettel). Considerando a relevância das interações sociais entre crianças para o desenvolvimento infantil, justifica-se a necessidade de investigar possíveis contextos que influenciam esse tipo de interação, o que é considerado como consensual para estudos nessa temática (Meneghini \& Camposde-Carvalho, 2003; Sager, Sperb, Roazzi, \& Martins, 2003). Essa linha de estudos vem sendo foco de interesse de diferentes estudos, como o de Sager e cols. (2003) que avaliou tipos de brincadeira e interação que ocorriam no pátio de uma escola e o de Meneghini e Campos-de-Carvalho (2003) que analisou a relação entre o arranjo ambiental e a ocorrência de categorias de interação em crianças em uma creche.

A brincadeira, por seu caráter espontâneo na infância, tem sido foco de estudos que atentam para situações que podem favorecer interações entre pares (Del Prette, Branco, Ceneviva, Almeida, \& Ades, 1986; Gil \& Almeida, 2000; Sager e cols., 2003). Como afirmam Queiroz, Maciel e Branco (2006), é por meio da interação com seus pares que a criança se envolve em processos de negociação, dentre os quais os de significação e ressignificação de si mesma, dos objetos, dos eventos e de situações, construindo e reconstruindo ativamente novos significados, e a brincadeira é uma atividade fundamental para isso.

Outra atividade em que as crianças se engajam com frequência, embora ainda pouco explorada como propiciadora de interações sociais, é o desenho. São poucos os estudos acerca da temática do desenho, e ainda mais raros aqueles que articulam desenho e interação social (Silva, 1998).

Para a abordagem sócio-histórica, ao contrário das teorias tradicionais sobre o grafismo, o desenvolvimento do desenho não se reduz a uma atividade solitária, caracterizada por etapas e desvinculada de seu contexto sociocultural. Ao encontro disso, no estudo de Araújo e Lacerda (2008), é defendida a necessidade de se rever a ênfase maturacionista na discussão sobre o desenho. As autoras, apoiadas em estudos nessa linha (Ferreira, Araújo, \& Lacerda; Silva, conforme citados por Araújo \& Lacerda, 2008), propõem a importância de se atentar mais para o impacto dos eventos interativos, principalmente os processos de linguagem, na atividade de desenho. Na perspectiva sócio-histórica, base de todos esses estudos, o desenho é concebido como um signo socialmente construído e, como tal, atua também como meio para o contato social.
Leite e Gobbi (2002) destacam que o desenho, enquanto produção criativa de crianças de zero a seis anos, tem sido desconsiderado como um espaço de troca que pode acarretar aprendizagem e desenvolvimento. Ao considerar o desenho na qualidade de produção a ser investigada e vista de maneira séria e singular, as autoras propõem, acima de tudo, que as crianças sejam consideradas "sujeitos singulares contextualizados, possuidores e criadores de história e de cultura, com especificidades em relação ao adulto" (p. 1).

O estudo de Silva (1998), por sua vez, admite essencialmente que o desenho precisa ser analisado à luz da participação do outro, visto que é a partir dessa participação que se dá o desenvolvimento do sujeito. De maneira inovadora e interessante, essa autora propõe a análise do processo de desenho e todas as trocas que dele podem emergir, não se restringindo ao produto final de uma atividade isolada.

Com tal perspectiva, o estudo de Silva (1998), realizado com crianças de três a cinco anos e frequentadoras de uma creche, procurou investigar o desenho como um processo socialmente constituído. Nesse estudo, foram focalizadas as interações que emergiam durante a atividade gráfica, as manipulações de materiais, bem como as relações entre fala e desenho. Tal pesquisa demonstrou que, em crianças mais jovens, a fala tem papel de organizar o grafismo e, com o aumento da idade, a fala passa a ter função de orientadora do desenho, corroborando as afirmações de Vygotsky (1988), ao descrever o conceito de fala planejadora da ação. $O$ estudo de Silva (1998) oferece, assim, a oportunidade de refletir acerca do caráter social do desenho e remete-nos à necessidade de ampliar as investigações do desenho como situação promotora de interações sociais importantes ao desenvolvimento da criança pequena.

O presente trabalho procurou identificar padrões de interação social que emergem na condição de produção gráfica (desenho) entre crianças pequenas. Para a produção gráfica, foram criadas quatro situações distintas: desenhar com giz de cera ou com guache; e desenhar individualmente em uma folha ou junto com outros colegas em uma mesma folha. Além disso, objetivou-se investigar características das interações sociais que emergiram, considerando a idade entendida como uma variável importante de análise.

\section{Método}

\section{Participantes}

Participaram deste estudo 28 crianças de dois a cinco anos, sendo 16 meninas (três de dois anos, seis de quatro, quatro de quatro e três de cinco) e 12 meninos (dois de dois anos, dois de três anos, quatro de quatro e quatro de cinco). Todas as crianças estavam matriculadas, em período integral, em uma creche assistencial de cidade de médio porte do Estado de São Paulo. As crianças participantes provinham de quatro diferentes salas divididas quanto à idade: Grupo I - dois anos (GI-2 anos), Grupo II - três anos (GII-3 anos), Grupo III - quatro anos (GIII-4 anos) e Grupo IV - cinco 
anos (GIV-5 anos). A opção pela faixa etária de dois a cinco anos baseia-se nos fatos de ser esse o período correspondente à educação infantil e de que nessa idade a criança já tem um controle motor fino que lhe permite usar os materiais relacionados ao desenho.

\section{Local/Equipamentos/Materiais}

A coleta de dados ocorreu na própria creche que as crianças frequentavam, em uma sala, de aproximadamente $9 \mathrm{~m}^{2}$, que possuía uma mesa com três cadeiras adequadas para crianças. Os equipamentos utilizados para registro e observação dos dados foram uma câmera filmadora, um tripé, videocassete e televisão. Os materiais utilizados para a atividade de desenho foram: duas caixas de giz de cera (cada uma com 12 gizes de diferentes cores, totalizando 24 unidades), guaches de quatro cores: amarelo, vermelho, verde e azul, três pincéis, papel branco de escritório tamanho A4 e cartolinas brancas.

\section{Procedimento}

O projeto foi submetido à apreciação do Comitê de Ética da Universidade Federal de São Carlos e aprovado. Com a aprovação da instituição, os pais das crianças que a frequentavam foram contatados, e aqueles que concordaram com a participação de seus filhos no estudo assinaram o Termo de Consentimento Livre Esclarecido (TCLE).

Anteriormente à coleta de dados propriamente dita, foi realizado um período de adaptação de uma semana, no qual a pesquisadora frequentava diariamente as salas de aula regulares das crianças participantes do estudo e engajava-se nas atividades lúdicas ou acadêmicas propostas pela educadora. Essas sessões tinham a duração de 30 minutos. Nos últimos dois dias de adaptação, a pesquisadora levou a câmera filmadora e permitiu que as crianças olhassem e tocassem tal equipamento.

Após isso, formaram-se trios de crianças de um mesmo grupo (em relação à idade) e, para isso, elas foram sorteadas, sendo que, para cada uma das quatro condições do estudo, era sorteado um novo trio. Cada trio era constituído por crianças que haviam participado de pelo menos uma sessão de adaptação. $\mathrm{O}$ trio sorteado era levado pela pesquisadora até a sala destinada à coleta. A câmera filmadora ficava disposta de maneira a focalizar simultaneamente todas as crianças do trio e suas respectivas atividades gráficas. Quando as crianças chegavam à sala, os materiais já estavam disponíveis em cima da mesa. Esses materiais diferiam de acordo com as condições seguintes:

(1) Giz de cera/individual: Duas caixas de giz de cera (cada uma com 12 unidades) que eram compartilhadas pelas crianças e uma folha de papel em branco para cada uma das crianças que desenhava em sua folha individualmente.

(2) Giz de cera/juntos: Duas caixas de giz de cera que eram compartilhadas pelas crianças, e uma cartolina branca que deveria ser usada, ao mesmo tempo, pelas três crianças.

(3) Guache/individual: Quatro potes de guache coloridos (vermelho, amarelo, verde e azul) colocados em copos plásticos; três pincéis (um para cada criança), além de uma folha de papel em branco que era entregue para cada criança que desenhava em sua folha individualmente.

(4) Guache/juntos: Quatro potes de guache (verde, vermelho, amarelo e azul), três pincéis (um para cada) e uma folha de cartolina branca que deveria ser usada ao mesmo tempo pelas três crianças.

Cada um dos grupos etários foi submetido às quatro condições, de modo que no estudo foram realizadas 16 sessões, de 15 minutos cada. Nas quatro condições, as crianças foram instruídas a desenhar o que quisessem, mas que deveriam compartilhar os gizes ou os guaches que estavam dispostos sobre a mesa. No caso das condições em grupo, a pesquisadora informava às crianças que elas deveriam utilizar a mesma folha com a seguinte instrução: "Aqui vocês têm uma folha e vão desenhar juntas nela”. O número de folhas não foi limitado em nenhuma das condições, sendo que, nas condições individuais (I e III), a pesquisadora fornecia nova folha tão logo a criança solicitasse. Nas condições em grupo (II e IV), era necessária a concordância das três crianças do grupo, após a solicitação de uma delas para que nova folha fosse liberada.

A pesquisadora só intervinha nas seguintes situações: quando houvesse interações agonísticas entre os participantes, o que ocorreu em raríssimas ocasiões. Outro tipo de intervenção que ocorria era quando se perguntava às crianças sobre o que cada uma havia desenhado, empregando-se sempre a mesma estrutura interrogativa: "Conta para mim: o que você está desenhando?” e, ainda, quando se elogiava o trabalho das crianças, após o relato do que tinham desenhado. Nas sessões em que as crianças requisitaram a participação da pesquisadora em suas interações, esta os orientou a fazerde-conta que ela não se encontrava na sala, com o objetivo de evitar interferências. A coleta somente terminou quando cada um dos grupos etários foi exposto a cada uma das quatro condições, pelo menos uma vez.

\section{Análise de dados}

No presente estudo, o conceito de interação social foi entendido como a ação recíproca entre, pelo menos, duas pessoas, caracterizando-o como um processo de troca, influência e regulação recíproca entre eles (Perosa, 1993). Para se proceder à análise dos dados, foram, inicialmente, realizadas as transcrições das sessões registradas e, com base nelas, foram identificadas e agrupadas as interações, utilizando-se como critério prioritário a funcionalidade da ação. As categorias de interação foram, então, nomeadas e definidas, conforme apresentadas abaixo com os seus respectivos exemplos.

Troca de olhares (TO): Comportamento de olhar em direção ao outro que também olha em direção a quem olhou. Exemplo: "B mantém-se olhando para $G$ que está fazendo movimentos circulares. G também olha para B".

Imitação (Imit): Sequência de comportamentos motores ou verbais de uma criança seguidos por ações similares 
(nomeação, movimento, produção gráfica, dentre outros) por parte da(s) outra(s) criança(s). Exemplo: "As crianças pintam. J olha para os movimentos de rabisco de B e também os faz. B olha para J e reproduz os mesmos movimentos”.

Solicitação 1 (atendida - Solic 1): Sequência de comportamentos verbais ou motores de uma criança, solicitando materiais ou alguma ação específica da(s) outra(s) criança(s), seguida de atendimento à solicitação. Exemplo: "L pega um giz verde do monte de F que está pegando um giz que caiu no chão. Quando ele volta a se sentar, L pergunta: Empresta? (mostrando o giz que pegou). F olha e não responde. L usa o giz".

Solicitação 2 (recusada - Solic 2): Sequência de comportamentos verbais de uma criança, solicitando materiais ou alguma ação específica da(s) outra(s) criança(s), seguida pela negação à solicitação pela(s) outra(s) criança(s). Exemplo: "B está desenhando na parte da folha que fica entre ela e I. B (Olha para I): Vou fazer uma água. I (percebe e a repreende): Para, B! (referindo-se a ela estar desenhando em tal espaço). B (continua desenhando): Tô fazendo um rio".

Instrução 1 (atendida - Inst 1): Sequência de comportamentos verbais e motores de uma criança oferecendo uma sugestão (exemplo: cor a ser usada) ou indicando às demais quais comportamentos devem ser emitidos para execução da atividade, seguida da concordância ou das ações que foram sugeridas, ou ainda, de pelo menos um olhar. Exemplo: "I senta-se ao lado de L e começa a instruí-la a respeito dos movimentos que devem ser executados para fazer uma estrela. I: $O$ ', faz assim (desenhando na parte da folha que está próxima de L), assim. L: Tá! I: Faz assim, assim. L: tá bom! (...)”.

Instrução 2 (recusada - Inst 2): Sequência de comportamentos verbais de uma criança indicando às demais quais comportamentos devem ser emitidos para execução da atividade e não acatados pela(s) outra(s) criança(s). Exemplo: "G (olha para B e seu desenho): Não. Não. Não! Não (coloca a mão sobre o desenho). Faz o dente. (A observa a interação). B (tira a mão de G de seu desenho): Não. Eu não consigo fazer com dente. (olha para G que não está olhando, pois já está desenhando)".

Avaliação 1 (concordante Aval 1): Sequência de comportamentos verbais de uma criança, emitindo julgamento ou interpretação sobre a ação ou sobre o produto do seu trabalho ou do de outra criança, seguida de concordância pela(s) outra(s) criança(s) ou pelo menos de um olhar. Exemplo: "P fala baixinho: Uma menininha! D repete: Uma menininha! Nunca vi uma menininha toda borrada. (P sorri e LG também) O’ Tia! A menininha da P toda borrada. P sorri. D: É feia, né? L (olha para D): É feia! Vai parecer um besouro (em relação ao desenho de P). P ri".

Avaliação 2 (discordante Aval 2): Sequência de comportamentos verbais de uma criança, emitindo julgamento ou interpretação sobre a ação ou sobre o produto do trabalho de outra criança, seguida de discordância da criança julgada ou de correção/complementação. Exemplo: "Tá tudo erra$d o$ ! (referindo-se ao desenho de L) L: $A i$ ! $B$ (com tom de discordância)".
Negociação (Negoc): Sequência de comportamentos verbais (ou motores) de uma criança, tendo em vista tanto o estabelecimento de regras a serem cumpridas como também a resolução de um conflito (divisão e utilização de materiais, etc.), seguida de aceitação por parte da(s) outra(s) criança(s) (seja por fala ou por ação). Exemplo: "L (olha para I com alguns gizes próximos a ela): Não! Cada um vai ficar com... um pouco (pega alguns gizes e dá a F). O F fica com esses. I também empurra alguns gizes para $\mathrm{F}^{\prime}$.

Descrição (Desc): Sequência de verbalizações que assumem o caráter de descrição de uma ação (presente, futura ou passada) ou de material disponível, acompanhada por concordância ou discordância; ou, ainda, no mínimo, de um olhar por parte de outra(s) criança(s). Exemplo: "T pega um giz e diz olhando para F: Eu peguei o laranja... é esse. Eu peguei o laranja; F olha para T que está usando o giz".

Oferecimento (Oferec): Sequência de comportamentos verbais e/ou motores de uma criança, disponibilizando materiais ou ajuda a outra(s) criança(s), acompanhada de aceitação da oferta. Exemplo: "B oferece um giz para G. $G$ (aceita): Peguei!"'.

Comentários Gerais (CG): Cantorias ou falas genéricas (relacionadas ao ambiente ou a algum evento externo) de uma criança, dirigidas a uma ou mais crianças, seguidas de comportamentos similares por parte da(s) mesma(s). Exemplo: "B (começa a cantar): Piripiriripiriri, (I e LG começam a cantar junto) alguém ligou pra mim. I (olha para B que olha): Sou eu bola de fogo (os três cantam). O calor tá de matar (enquanto pintam)".

Conflito (Conf): Sequência de comportamentos verbais ou motores com caráter de acusação / provocação, de disputa, de recusa em dividir material ou de agressão física ou verbal, seguida por comportamentos semelhantes por parte da outra criança, verbalizações defensivas e/ou discordantes; ou, ainda, por pelo menos um olhar. Exemplo: "G (olha para B): Não é para fazer aí. B (continua fazendo): Eu quero fazer. $\mathrm{G}$ (bate duas vezes no braço de $\mathrm{B}$ ): $A h$ ! B! B olha para $\mathrm{G}$ e para a pesquisadora (...)".

Demonstração (Mos): Sequência de comportamentos motores ou verbais de uma criança, dirigida a uma outra criança, que responde pelo menos com um olhar. Exemplo: “ $G$ : O’ O meu papai ieiél (duas vezes). B olha e diz: Papai ieiél, papai ieiél’.

Indagação (Ind): Sequência de comportamentos verbais de uma criança com a função de perguntar sobre a produção gráfica ou ação relacionada, acompanhada de resposta ou de ao menos um olhar por parte de outra(s) criança(s). Exemplo: "L: Como você fez, I? I (enquanto desenha): Eu fiz aqui, depois aqui, depois aqui, depois aqui... (faz traços que formam uma estrela). $L:$ Ah! Entendi (...)".

Enredo (Enr): Sequência de comportamentos verbais que contextualizam a produção gráfica, seguida de comportamentos verbais de complementação ou correção da fala; ou, ainda, de apenas um olhar. Exemplo: “D: Ó, o peixinho. (P e LG olham e D continua desenhando). Ó, quanta bolinha 
ele tá soltando (faz pinguinhos próximos ao desenho). $\mathrm{P}$ observa e sorri".

Por dificuldade em serem obtidos juízes voluntários, não foi realizado cálculo de fidedignidade, utilizando-se observadores independentes, mas a classificação das interações identificadas em cada uma das sessões foi feita mais de uma vez pelo próprio pesquisador sem consulta à classificação prévia. Desse modo, obteve-se uma segunda checagem da categorização, sendo que cada interação poderia ser classificada em apenas uma categoria. Ao final desse procedimento, foram identificadas 16 categorias que compõem o sistema de categorias já apresentado anteriormente.

Uma vez classificadas as categorias, estas foram transpostas para um protocolo de registro, sessão a sessão, tendo sido computada a frequência de cada categoria interativa em cada sessão, obtendo-se, assim, a frequência total de interações de cada sessão e a frequência de cada categoria por sessão. $\mathrm{O}$ cálculo da porcentagem das diferentes categorias interativas de cada grupo etário, apresentado na Figura 1, ou de cada condição de produção gráfica, apresentado na Figura 2, foi feito considerando-se o total das interações ocorridas em cada uma dessas diferentes situações - grupo etário ou condição de produção.

\section{Resultados e Discussão}

O primeiro aspecto a ser destacado é que, diferentemente do apontado por vários autores (Lurçat, 1988; Luquet, 1976), a condição de desenho pode favorecer uma alta frequência de interações entre crianças (total de interações=728), corroborando estudos de Silva (1998) e de Leite e Gobbi (2002) que admitem o desenho como um meio para o contato social. Já no que se refere à idade, no geral foi observado um aumento gradual da frequência total de interações com o avanço da idade das crianças (GI=122 ou 17\%; GII=202 ou $28 \%$; GIII=229 ou $31 \%$ e GIV=175 ou $24 \%$ ). Com relação aos tipos de interações que emergiram no contexto de desenho, as categorias Descrição e Imitação (respectivamente, 123 e 104) foram as que mais se destacaram, ao passo que as categorias Enredo e Negociação tiveram menor número de ocorrência (respectivamente, 11 e 16).

A Figura 1 apresenta a porcentagem de ocorrência das categorias interativas nas sessões para cada grupo etário. É importante mencionar que as porcentagens das categorias foram calculadas, considerando-se o total de interações ocorridas em cada um dos grupos etários, a saber: $\mathrm{GI}=122$; $\mathrm{GII}=202 ; \mathrm{GIII}=229$ e $\mathrm{GIV}=175$.

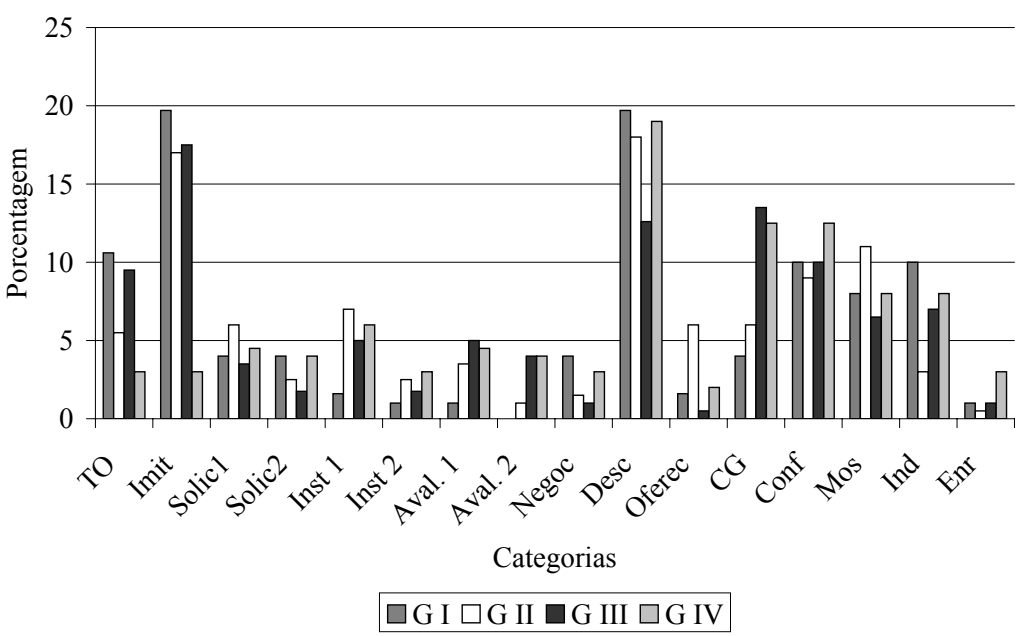

Figura 1. Porcentagem de ocorrência das categorias interativas com base no total de interações para cada um dos grupos etários (GI-2 anos, GII-3 anos, GIII-4 anos, GIV-5 anos).

Com base na Figura 1, ao se compararem as porcentagens das categorias nos diferentes grupos etários, podese observar que a categoria Descrição foi mais frequente em todos os grupos $(\mathrm{GI}=19,7 \%, \mathrm{GII}=18 \%, \mathrm{GIII}=12,6 \%$, GIV $=19 \%$ ), assim como a categoria Imitação, excetuando-se, no último caso, o GIV (GI=19,7\%, GII=17\%, $\mathrm{GIII}=17,5 \%$, GIV=3\%). Em seguida, observa-se destaque das categorias Conflito $(\mathrm{GI}=10 \%, \mathrm{GII}=9 \%, \mathrm{GIII}=10 \%$, $\mathrm{GIV}=12,5 \%)$ e Demonstração em todos os grupos ( $\mathrm{GI}=8 \%$ $\mathrm{GII}=11 \%, \mathrm{GIII}=6,5 \%$ e GIV=8\%). Já as categorias interativas com menores porcentagens em todos os grupos etários foram: Enredo $(\mathrm{GI}=1 \%, \mathrm{GII}=0,5 \%, \mathrm{GIII}=1 \%$, GIV=3\%),
Instrução $2(\mathrm{GI}=1 \%, \mathrm{GII}=7 \%, \mathrm{GIII}=5 \%$ e $\mathrm{GIV}=6 \%)$ e Avaliação $2(\mathrm{GI}=0 \%, \mathrm{GII}=1 \%$, GIII=4\%, GIV=4\%).

Com relação à categoria Conflito, embora os quatro grupos tenham apresentado frequências semelhantes, ao se atentar para a natureza dos conflitos, notam-se algumas diferenças, como nos exemplos envolvendo conflitos nos GI-2 anos e GIV-5 anos, descritos a seguir:

GI-2 anos: G (olha para o pote de tinta perto dela, ela vê B pegando-o): Tia, é minha! Ó tia, ela pegou Papai Noel minha (referindo-se ao pote vermelho). B: não peguei não, não peguei. Tô pintando. G(olha 
para B): É? B não olha, pois está pintando. B: não peguei o papai Noel. G: Tá pegando.

GIV-5 anos: L (começa a cantar enquanto desenha): Sou uma árvore tão velha que ninguém gosta mais de mim... B (olha para L cantando e canta também): mas quem gosta de você é seu pai e sua mãe. Isso dai nem é uma árvore. L: Para, fica quieto! Deixa eu desenhar o que eu quero. B: Isso não é uma árvore. L: Para, B! (com voz brava). B: Ah! Que é que tem? deixa eu falar... (continua olhando para o desenho de L). Isso dai não é uma pipa. L: Ah! Fica quieto, B! Eu faço o que eu quero. B: Nossa! Tá tudo feio. L: $O$ seu... tá tudo horrivel. (B olha para seu desenho). B e $L$ insultam um ao outro repetidas vezes. $L$ bate na mão de B e a In diz que não é para fazer aquilo.

A primeira sequência de interações apresentada exemplifica o tipo de conflito que mais ocorreu para o GI-2 anos, que, em geral, estava relacionado à disputa de materiais, uma vez que as crianças dessa idade pareciam assumi-los como se fossem de posse individual. Já no GII-3 anos, além dos conflitos dessa ordem, também houve aqueles que envolviam provocação. No GIII-4 anos, ocorreu uma maior diversidade das interações categorizadas como Conflito - além da disputa por materiais, ocorreram provocações e, particularmente, acusações. Quanto ao GIV-5 anos, pode-se notar, no exemplo da categoria Conflitos anteriormente descrito, que a sequência interativa é mais complexa e apresenta uma diversidade de outras categorias interativas, como: Solicitação 2 (quando $\mathrm{L}$ pede para $\mathrm{B}$ parar e esse não para), Avaliação 2 (retribuição de L à fala avaliativa de B: "o seu que tá horrível”) e culminando com o conflito propriamente, o qual envolveu tanto agressão verbal como física. Essa maior complexidade e diversidade estão, provavelmente, relacionadas ao fator idade, uma vez que tanto a linguagem como a capacidade cognitiva aumentam em função dela.

Situações similares foram observadas para outras categorias. Assim, ao se compararem os grupos mais jovens (GI-2 anos e GII-3 anos) e os mais velhos (GIII-4 anos e GIV-5 anos), verificou-se que as categorias Comentários gerais e Avaliação 2 tiveram porcentagens mais elevadas nos grupos mais velhos (GIII-4 anos $=13,5 \%$ e $4 \%$; GIV-5 anos $=12,5 \%$ e $4 \%$, respectivamente). Ainda, comparando-se os resultados dos Grupos I-2 anos e IV-5 anos, observa-se que as interações mais simples tiveram maior ocorrência no GI-2 anos (Troca de olhares $=10,6 \%$ e Imitação $=20 \%$ ) e menor no GIV-5 anos (Troca de olhares $=3 \%$ e Imitação=3\%). Já na categoria Enre$d o$, embora sua ocorrência tenha sido baixa (11), nota-se um aumento gradativo com o avanço na idade das crianças: no grupo dos mais velhos (GIII-4 anos e GIV-5 anos) ocorreram nove interações da categoria Enredo, contra apenas duas nos grupos mais jovens (uma para cada grupo: GI-2 anos e GII-3 anos). Esse dado, de forma semelhante à análise feita anteriormente, pode ser justificado ao se considerarem as características das ações definidoras dessa categoria, que exigem maiores avanços não só na socialização como também no desenvolvimento da linguagem verbal e cognição.

Com base na Figura 1, observa-se que houve uma maior diversidade de interações para os grupos mais velhos em comparação aos mais jovens. Isto é, nos grupos mais novos (GI-2 anos e GII-3 anos), nem todas as categorias interativas foram observadas nas sessões experimentais, ao passo que nos grupos mais velhos ocorreram todas as categorias identificadas neste estudo.

Com relação às condições de produção, a de guache/juntos foi a que apresentou a mais alta frequência de interações na maioria dos grupos (211), ao passo que a condição giz de cera/ individual teve a menor (139). Conforme a Figura 2 pode-se verificar a porcentagem de ocorrência de cada uma das categorias interativas em relação ao total de interações ocorridas, durante cada uma das condições. De forma similar à Figura 1 , as porcentagens das categorias foram calculadas considerando-se o total de interações ocorridas em cada uma das condições experimentais, a saber: giz/individual=139, giz/ juntos $=187$, guache/individual $=191$ e guache/juntos $=211$.

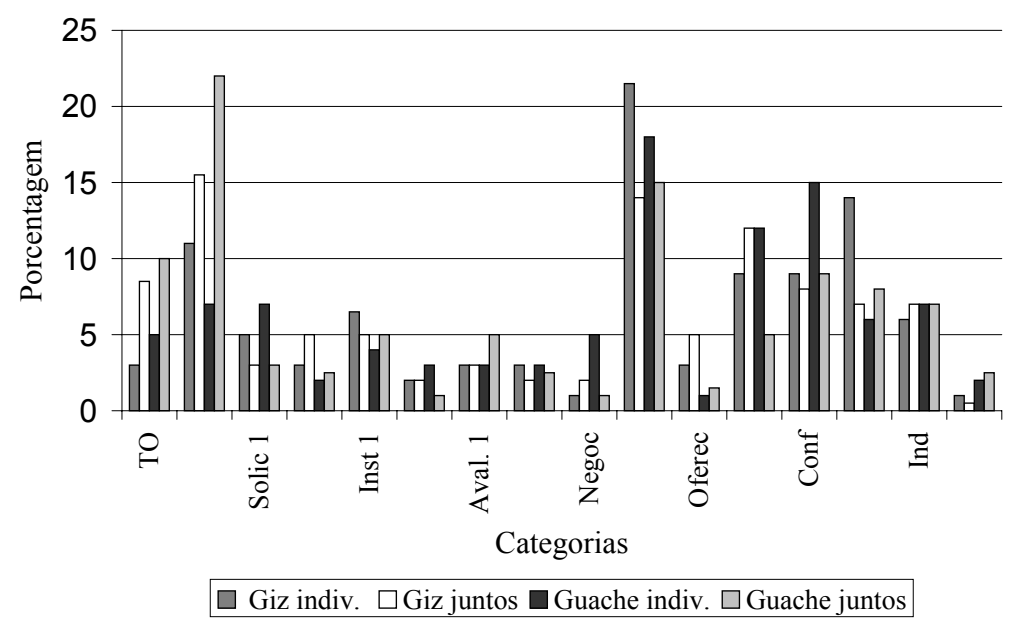

Figura 2. Porcentagem de ocorrência das categorias interativas com base no total de interações para cada uma das quatro condições de produção gráfica. 
Na Figura 2, pode-se observar que a categoria Descrição teve alta porcentagem de ocorrência em todas as quatro condições do estudo, com variação de $14,5 \%$ na condição giz de cera/juntos a $21 \%$ na condição giz de cera/individual. A categoria Imitação também apresentou alta porcentagem de ocorrência em todas as condições, exceto na condição guache/individual. As categorias que apresentaram menor frequência em todas as condições foram Enredo - variando de $0,5 \%$ na condição giz de cera/juntos a $2,5 \%$ na condição guache /juntos -, Instrução 2 - entre $1 \%$ na condição de guache/juntos e 3\% na de guache/ individual, e Negociação com variação de $1 \%$ nas condições de giz de cera/ individual e guache/ juntos a $5 \%$ na de guache/ individual.

Quando se comparam as frequências de ocorrência em termos de dados absolutos, observa-se que, na categoria $E n$ redo, apesar de sua baixa ocorrência (11) no estudo, encontrou-se uma pequena diferença entre o número de ocorrências obtidas nas condições com guache (guache/juntos $=5$ e guache/individual $=4$, totalizando 9 ocorrências) com o número de ocorrência desta mesma categoria nas condições com o material giz (giz de cera/individual=1 e giz de cera/juntos $=1$, totalizando 2 ocorrências). Tais resultados podem sugerir que as condições com guache talvez favoreçam a ocorrência de interações mais complexas como a categoria Enredo, as quais requerem um desenvolvimento mais elaborado (tanto social, como cognitivo e da linguagem) por parte da criança, o que poderá ser objeto de investigações futuras.

Ao observar as Figuras 1 e 2, verifica-se que algumas categorias mantiveram-se altas na maioria das idades e condições, tais como as categorias Descrição e Imitação, exceto o GIV-5 anos que apresentou baixa ocorrência de Imitação, como mostrado na Figura 1. Em relação à categoria Descrição, uma possível explicação está relacionada ao fato, amplamente apontado pela perspectiva sócio-histórica, de que as crianças pequenas, por ainda não terem a fala internalizada como os adultos, apresentam suas ações acompanhadas de descrição com vistas a organizar ou planejar suas condutas (Leontiev, Luria, \& Vygostky, 1988). No que se refere à categoria Imitação, sua alta frequência no estudo pode estar associada ao fato de o comportamento imitativo fazer parte do repertório da criança desde muito cedo, e as crianças mais novas aprenderem fundamentalmente por meio da imitação. Embora se tenha admitido por algum tempo ser a imitação uma forma inferior de interação, atualmente já é reconhecido que a imitação tem um papel fundamental na socialização de crianças pequenas, como foi sugerido por Carvalho (1989), sendo também uma das maneiras principais de a criança ampliar seu repertório de ações.

É importante, contudo, ressaltar que foram observadas diferenças na natureza das imitações, ao se compararem aquelas imitações apresentadas pelos GI-2 anos e GII-3 anos com as do GIII-4 anos. Assim, embora topograficamente a imitação fosse semelhante entre os grupos, em relação à função ela se diferenciava, pois enquanto no GI-2 anos e GI-3 anos essa imitação consistia na reprodução do comportamento emitido previamente pelo parceiro, no GIII-4 anos a maioria dos comportamentos imitativos era de natureza lúdica, ou seja, as crianças imitavam para gracejar. Os exemplos apresentados, a seguir, podem ilustrar essa afirmativa.

GI-2 anos: B (olhando para o giz cor-de-rosa em sua mão): Tô passando... Meu batom. (olha para J que olha). Enquanto isso, G também está passando o giz em seu lábio. $\mathrm{G}$ (olha para $\mathrm{B}$, movimentando o giz nos lábios): Meu batom... (B olha) G e B olham um para o outro e continuam com o movimento de passar o giz no lábio.

GIII-4 anos: I (desenhando): O ovo da Pácoa. B (olha e sorri para I): $O$ ovo da páppaa (imitando o erro de I). I (enquanto desenha): O ovo da papinha. LG (rindo): o ovo da papatinha. B: O Ovo da Páscoa! I (fazendo voz fina): O ovo da Páscoa.

Pela análise comparativa dos trechos acima, pode-se verificar, portanto, que as interações imitativas apresentaram diferentes características em relação à idade. Enquanto para os menores as interações imitativas eram menos complexas e caracterizavam-se pela repetição de verbalizações ou de ações não relacionadas ao desenhar, nos grupos mais velhos, além de a imitação referir-se à reprodução da ação (gráfica), também poderia ter uma função lúdica, produzindo momentos de descontração enquanto as crianças desenhavam.

Esses aspectos podem ser ilustrados pelas diferentes análises e experimentações que foram feitas também em relação ao giz branco, havendo variações significativas de acordo com a idade das crianças. Exemplos nos grupos etários das diferentes experimentações do giz branco são apresentados a seguir:

GI-2 anos: Gy pega o giz branco, escreve um pouco e diz: Gy: Esse não tem ponta! (em tom de reclamação) J oferece outro giz dizendo: J: Esse aqui tem, oh! Gy: Esse não tem ponta. (olhando para J que também está olhando). J diz que não com a cabeça. K observa. Gy: esse tem ponta? (voltando a pegar o giz da cor branca). J: Tia, esse não tem ponta.

GIII-4 anos: LG (olha onde B desenhou); $A i ! A B$ rabiscou a mão (...) a mesa. (usando o giz branco). Vou apagar (dá risada). B observa e também ri.

GIV-5 anos: (...) I: O branco não pega! L: mas o branco serve pra pintar, né?! (olhando para In). Quando tem uma cor. L (olha para o desenho de B): Ah, B. De preto? L: Vou fazer de branco (pega um giz branco no meio). Branco não pega, aí, ó B observa $L$ pintando na folha com o giz branco e pega dela: Assim, ó! L (olha): Só sente (passando o dedo na parte pintada com o giz branco). 
Ao serem comparadas as análises e experimentações feitas pelos diferentes grupos envolvendo a cor branca, observa-se que, para as crianças do GI-2 anos, os traços do giz branco não apareciam na folha porque o giz não tinha ponta. Já nos grupos mais velhos, as crianças acreditavam que o giz servia para apagar (como uma borracha) traços produzidos pelos gizes coloridos, como LG fez, ou tinham a função de produzir um efeito de alto-relevo (o sentir apenas), de maneira que as crianças usavam-no, em geral, em cima de outra cor, como se vê no trecho. Baseando-se nesse fato, é possível verificar que a exploração do giz branco criou conflitos cognitivos entre as crianças, os quais foram solucionados com o apoio de outras crianças. Isso é concordante com o que Salvador (1990/1994) argumenta a favor das interações entre pares, por envolver uma simetria que cria condições para a aprendizagem.

As interações que ocorrem entre coetâneos podem ser também importantes para a aprendizagem e o desenvolvimento, uma vez que é a partir de interações mais simétricas que esses dois processos podem acontecer de maneira mais espontânea e lúdica em situações do cotidiano infantil. Desse modo, nos dois grupos mais velhos, foram observados alguns momentos nos quais o contexto de desenho oportunizou interações que se relacionavam à contagem de números, como será apresentado a seguir:

GIV-5 anos: I: Eu tenho 1,2,3,4,5,6,7 (olha para o monte de L). O teu tem sete. (L olha para I e então começa a contar, enquanto $\mathrm{F}$ e I observam): $1,2,3,4,5,6,7$ e 8 (fica um giz em sua mão - F e I se olham enquanto L conta). Aqui tem (olha para F) $o$ vermelho é do $F$, aqui tem 7. (mostrando o monte que contou). Aqui, aqui, ó. Com esse (junta o giz que estava em sua mão e olha para I) dá 8,8 . (I não olha e continua manipulando seus gizes). F estende sua mão e mostra seu monte para L. L: Deixa eu ver quantos você tem. F (tira de perto de L): Eu tenho pouquinho. L: conta! F conta em voz baixa. I (olha para $\mathrm{F}$ contando): Não é assim que conta. É assim, ó 1,2,3,4 (vai contando e passando os gizes de uma mão para outra). 5, 6, 7,8,9. L e F observam I contar. L: Você tem nove! F começa a contar. I olha e conta junto com ele: 1,2,3,4. I: $5 \mathrm{~F}$ (não mais contando): Para de imitar eu! I: eu tava olhando pra contar pra você. I volta a contar e novamente I acompanha-o na contagem. F para de contar. I: dá aí que eu conto pra você! F recolhe os gizes. I: $\dot{E}$ assim, ó (conta passando os gizes de uma mão para outra). Ela deixa os gizes caírem e então recomeça a contar. F observa I contando e depois começa a contar seu monte também e logo para.

No trecho acima sobre a contagem de números, notase que Ia e Lo são parceiras mais experientes de uma Zona de Desenvolvimento Proximal (ZDP), conforme conceito apresentado por Vygotsky (1988), de maneira que seria possível a efetivação do desenvolvimento proximal em real por parte de $\mathrm{F}$, já que as meninas dominam a contagem de números, embora $\mathrm{F}$ ainda não seja capaz. Isso caracteriza o que é chamado por Vygotsky de desenvolvimento proximal uma vez que, como indica Machado (1992), esse só é concretizado e transforma-se em possibilidade de se tornar desenvolvimento real em interação na qual existam parceiros com níveis diferenciados de conhecimento (adultos ou pares mais capazes). O parceiro com nível diferenciado (Ia), no entanto, embora se tenha proposto a ajudar, recebeu a recusa do parceiro menos capaz, e a interação foi, então, interrompida.

Em síntese, os resultados do presente estudo indicaram que: (1) o contexto de desenho é promotor de interações sociais entre crianças (728 ocorrências) e pode constituir-se em condição favorável ao desenvolvimento; (2) os tipos de interações variam quando se considera a idade; (3) não houve grandes variações nas categorias interativas, quando se consideram as diferentes condições de desenho utilizadas.

\section{Considerações finais}

Com base nos resultados obtidos no presente estudo, verifica-se que, à semelhança do que afirmou Silva (1998), o desenho pode ser promotor de interações sociais com conteúdos variados. Assim, ao considerar que as interações sociais, segundo Vygostky (1988), são a base para o desenvolvimento do sujeito, o contexto desenho pode também ser explorado como promotor de desenvolvimento infantil, o que já é feito amplamente em relação a outros tipos de brincadeira, como o faz-de-conta.

Valendo-se dos resultados deste estudo, mesmo ao se considerar que o sistema de categorias adotado foi produto do recorte do pesquisador, é possível supor que as interações entre as crianças apresentaram bastante diversidade. Isso pôde ser evidenciado pelas 16 categorias identificadas, as quais envolveram desde interações mais simples, como as categorias Imitação e Troca de Olhares, até as mais complexas, como as categorias Enredo e Avaliação 1 e 2. Nesse sentido, escolas de educação infantil poderiam explorar mais o momento de desenhar da criança, desde que esteja associado à brincadeira e tenha a intenção de beneficiar o grupo e não como uma imposição ou obrigação, impedindo-a de decidir ou não sua inserção na atividade (Queiroz e cols., 2006). Ou, ainda como sugere Silva (1998), não seja apenas um momento para a criança "passar o tempo", mas atue como uma atividade que oportuniza trocas sociais ricas e espontâneas que favorecem ganhos em diversas áreas do desenvolvimento.

A adoção dessa atividade, também como forma de se promoverem trocas entre crianças, pode ser justificada pelos dados do presente estudo e por uma ampla literatura na área de desenvolvimento que destaca a relevância das interações entre pares para o desenvolvimento infantil (Carvalho, 1989; Oliveira \& Rossetti-Ferreira, 1993). Conforme destacado por Salvador (1990/1994), a simetria e a espontaneidade 
presentes nas interações entre crianças, como pode ocorrer durante a atividade do desenho, criam condições ótimas de aprendizagem e, portanto, de desenvolvimento de inúmeros aspectos, como já foi apontado por Branco e Mettel (1995).

Ainda, por meio da atividade gráfica, a criança entra em contato com o mundo simbólico do grafismo, com contribuições potenciais singulares para a cognição, ao mesmo tempo em que se engaja em trocas sociais diversificadas que envolvem a aprendizagem de regras sociais, a participação do outro na produção e as interações de ideias. Todos esses aspectos requerem, cada vez mais, um papel de destaque para a linguagem.

Um fator importante nas aquisições ocorridas em diferentes áreas do desenvolvimento refere-se ao avanço da idade. Os resultados do presente estudo mostraram que, com o aumento da idade, há uma maior frequência de interações e, particularmente, o aumento na complexidade e diversidade delas. Enfim, os resultados do presente estudo confirmaram que o contexto desenho pode ser promotor de interações sociais frequentes e diversas, podendo favorecer interações sociais entre crianças que envolvam partilhar ou trocar objetos, comunicar ideias, oferecer sugestões, entre outros. Desse modo, o desenho poderia ser explorado no contexto de planejamento das atividades de educação infantil. Além disso, o avanço na idade interferiu principalmente na qualidade das interações ocorridas, o que pode estar muito relacionado com a evolução do domínio da linguagem pelas crianças maiores.

\section{Referências}

Amorim, K. S., Vitória, T., \& Rossetti-Ferreira, M. C. (2000). Rede de significações: Perspectiva para análise da inserção de bebês na creche. Cadernos de Pesquisa, 109, 115-144.

Amorim, K. S., Eltink, C., Vitória, T., Almeida, L. S., \& Rossetti-Ferreira, M. C. (2004). Processos de adaptação de bebês à creche. In M. C. Rossetti-Ferreira, K. S. Amorim, A. P. Soares-Silva, \& A. M. A. Carvalho (Orgs.), Rede de significações e o estudo do desenvolvimento humano (pp. 137-156). Porto Alegre: Artmed.

Araújo, C. C. M., \& Lacerda, C. B. F. (2008). Examinando o desenho infantil como recurso terapêutico para o desenvolvimento de linguagem de crianças surdas. Revista da Sociedade Brasileira de Fonoaudiologia, 13, 186-192

Branco, A. M. U., \& Mettel, T. P. L. (1995). Canalização cultural das interações criança-criança na pré-escola. Psicologia: Teoria e Pesquisa, 11, 13-22.

Carvalho, A. M. A. (1989). Brincar juntos: Natureza e função da interação entre crianças. In C. Ades (Org.), Etologia de animais e homens (pp. 199-210). São Paulo: Edicon/ Edusp.

Colaço, V. F. R. (2004). Processos interacionais e a construção de conhecimento e subjetividade de crianças. Psicologia: Reflexão e Crítica, 17, 333-340.
Del Prette, A., Branco, A. M. U., Ceneviva, M. S. A. G., Almeida, N. V. F., \& Ades, C. (1986). A utilização do objeto nas interações pró-sociais apresentadas por crianças da pré-escola. Psicologia: Teoria e Pesquisa, 2, 245-264.

Del Prette, Z. A. P., \& Del Prette, A. (2005). Psicologia das habilidades sociais na infância: Teoria e prática. Petrópolis, RJ: Vozes.

Gil, M. S. C. A., \& Almeida, N. V. F. (2000). Padrões de interação entre mãe e bebê em situação de brincadeira. Cadernos de Psicologia, 10(1), 89-102.

Gil, M. S. C. A., \& Almeida, N. V. F. (2005). Estudos avançados do desenvolvimento infantil (Série Apontamentos). São Carlos: EdUFSCar.

Isaia, S. M. A (1998). Contribuições da teoria vygotskiana para uma fundamentação psico-epistemológica da educação. In V. M. R. Vasconcellos (Org.), Vygotsky um século depois (pp. 21-34). Minas Gerais: EdUFJF.

Leite, M. I., \& Gobbi, M. (2002). O desenho da criança pequena: Distintas abordagens na produção acadêmica em diálogo com a educação. In M. I. Leite. (Org.), Ata e desata: Partilhando uma experiência de formação continuada (pp. 93-148). Rio de Janeiro: Ravil.

Leontiev, A., Luria, A. R., \& Vygostsky, L. S. (1988). Linguagem, desenvolvimento e aprendizagem. São Paulo: Ícone.

Lordelo, E. R., \& Carvalho, A. M. A. (1998). Creche como contexto de desenvolvimento: Parcerias adulto-criança e criança-criança. Temas em Psicologia, 6, 117-124.

Luquet, G. H. (1976). El dibujo infantil. Barcelona, Espanha: Editorial Medica y Técnica.

Lurçat, L. (1988). Pintar, dibujar, escribir, pensar: El grafismo en el preescolar. Madrid: Cincel.

Machado, M. L. A. (1992). Educação infantil e sóciointeracionismo. In Z. M. R Oliveira (Org.), Educação infantil: Muitos olhares (pp. 25-50). São Paulo: Cortez.

Meneghini, R., \& Campos-de-Carvalho, M. (2003). Arranjo espacial na creche: Espaços para interagir, brincar isoladamente, dirigir-se socialmente e observar o outro. Psicologia: Reflexão e Crítica, 16, 367-378.

Oliveira, Z. M. R., \& Rossetti-Ferreira, M. C. (1993). $\mathrm{O}$ valor da interação criança-criança em creches no desenvolvimento infantil. Caderno de Pesquisa, 87, $62-70$.

Perosa, G. B. (1993). O conceito de interação nos estudos com crianças pequenas. Psicologia: Teoria e Pesquisa, 9, 401-403.

Queiroz, N. L. N., Maciel, D. A., \& Branco, A. U. (2006). Brincadeira e desenvolvimento infantil: Um olhar sociocultural construtivista. Paideia (Ribeirão Preto), 16, 169-179.

Sager, F., Sperb, T. M., Roazzi, A., \& Martins, F. M. (2003). Avaliação da interação de crianças em pátios de escolas infantis: Uma abordagem da psicologia ambiental. Psicologia: Reflexão e Crítica, 16, 203-216. 
Salvador, C. C. (1994). Aprendizagem escolar e construção de conhecimento (E. O. Dihel, Trad.). Porto Alegre: Artes Médicas. (Original publicado em 1990)

Silva, S. M. C. (1998). Condições sociais da constituição do desenho infantil. Psicologia USP, 9(2), 205-220.

Vygotsky, L. S. (1988). A formação social da mente. São Paulo: Martins Fontes.

Talita Pereira Dias é mestranda no Programa de Pós-graduação em Psicologia da Universidade Federal de São Carlos, bolsista da FAPESP.

Nancy Vinagre Fonseca de Almeida é Professora Adjunta do Departamento de Psicologia da Universidade Federal de São Carlos, campus São Carlos.

Recebido: $14 / 05 / 2008$

$1^{a}$ revisão: $10 / 10 / 2008$

$2^{a}$ revisão: 03/02/2009

$3^{a}$ revisão: $10 / 07 / 2009$

Aceite final: $12 / 08 / 2009$ 